\title{
NATURE OF DIELECTRIC RELAXATION IN MICROCRYSTALLINE CELLULOSE
}

\author{
OLEXANDER M. ALEKSEEV, ${ }^{*}$ KOSTIANTYN M. KOVALOV, ${ }^{*}$ MAXIM M. LAZARENKO, \\ MYKHAILO V. LAZARENKO, ${ }^{* *}$ YURII E. GRABOVSKII" ${ }^{*}$ and SERGII YU. TKACHOV* \\ "Taras Shevchenko National University of Kyiv, 64/13, Volodymyrska Str., Kyiv 01601, Ukraine \\ ${ }^{* *}$ National University of Food Technologies, 68, Volodymyrska Str., Kyiv 01601, Ukraine \\ $\bowtie$ Corresponding author: Sergey Tkachev, tkachevserg@gmail.com
}

Received February 12, 2018

\begin{abstract}
This article is devoted to the investigation of microcrystalline cellulose (MCC). X-ray diffraction analysis allowed estimating the radius of microcrystalline cellulose particles (whiskers), while the dielectric spectroscopy method gave an insight into the mean-square change of the dipole moment per unit volume and the concentration of relaxers as a result. The moisture content of the MCC samples was estimated using thermogravimetric analysis. According to the experimentally obtained data, we propose a model to describe the dipole relaxation in MCC as being caused by reorientation of hydroxymethyl groups only on the surface of a microcrystalline cellulose particle.
\end{abstract}

Keywords: microcrystalline cellulose, X-ray diffraction analysis, dielectric spectroscopy, dipole motion

\section{INTRODUCTION}

Cellulose is a natural polymer, which serves as basis for the development of a wide range of industrial materials. The high practical value of cellulose and its derivatives determines the necessity to study the structural features of this macromolecule as a function of its chemical and physical modifications. Among the structural modifications of cellulose, microcrystalline cellulose (MCC) ranks as the most significant one. The structure and properties of MCC distinguish it from traditional fibrous or powder celluloses, and allow its further chemical modification to obtain biologically active derivatives. $^{1}$

By various methods, including the dielectric one, it has been established that several thermally initiated relaxation and phase transitions exist in cellulose and its derivatives. ${ }^{2-5}$ The degree of manifestation of such transitions with regard to particular properties is different, since various factors have an impact on their behavior, in particular, the crystallinity and the presence of water. It is known that the supermolecular structure considerably affects the physical properties, including dielectric polarization. For the majority of amorphous-crystalline polymers, the processes of thermal dipole relaxation take place in the amorphous part of the system, while in the crystalline part, they can be completely "frozen". There are two models describing dielectric relaxation in cellulose and its derivatives. The work of T. I. Borisova et al. ${ }^{3}$ shows that low-temperature relaxation in polysaccharides is due to the movement of hydroxymethyl groups, while J. Einfeldt et al. ${ }^{4,5}$ state that relaxation is connected with the local movement of chain segments linked by glycosidic bonds. It has been established that, in cellulose, ${ }^{3}$ the effect of crystallinity influences (depresses) the dielectric relaxation.

However, it is not clear if it is absent in a crystal, in which the presence of segmental motion of chains is unlikely, while the movement of hydroxymethyl groups on the surface of crystallites is possible. In the works of D. Le Bras et al., ${ }^{2}$ and T. I. Borisova et al., ${ }^{3}$ it was shown that the increase of the moisture content shifts the temperature range in which dielectric relaxation is observed toward lower temperatures. The question is whether there is dielectric relaxation in crystalline cellulose and whether it is possible in the absence of water. Therefore, in order to understand the dielectric relaxation mechanism in crystalline cellulose, we have investigated 
microcrystalline cellulose with a minimal amount of moisture.

Numerous publications are devoted to the study of dielectric relaxation in MCC, ${ }^{1,2}$ however, the molecular mechanism of the relaxation remains unexplained. The aim of this work is to investigate dielectric relaxation in microcrystalline cellulose and fill in some knowledge gaps existing in this research area.

\section{EXPERIMENTAL Materials}

Cellets 100 MCC (Shin-Etsu Chemical Co.) was used in the present investigation. Initial samples were fractionated in an agate mortar. After grinding, the average particle size was $10 \mu \mathrm{m}$. The samples of MCC were kept in a drying oven for 3 days at a temperature of $115^{\circ} \mathrm{C}$.

\section{Methods}

Powder diffraction analysis was performed using a DRON-3M X-Ray diffractometer, with a BSV-28 tube $(\mathrm{Cu} \mathrm{K} \alpha, \lambda=1.54178 \AA)$.

Thermogravimetric analysis (TGA) and differential thermal analysis (DTA) were performed using a Q$1500 \mathrm{D}$ derivatograph. The measurements were made within the temperature range of $\mathrm{T}=(20 \div 250){ }^{\circ} \mathrm{C}$ and with the heating rate of $5^{\circ} \mathrm{C} / \mathrm{min} .{ }^{6,7}$

The samples for the dielectric investigation were prepared by pressing MCC powder, under vacuum at $10^{-2} \mathrm{~mm} \mathrm{Hg}$, at a pressure of $36 \mathrm{MPa}$, after previously drying this powder at $105{ }^{\circ} \mathrm{C}$ during 30 minutes for final removal of moisture. Samples with the diameter of $45 \mathrm{~mm}$ and thickness of $0.5 \mathrm{~mm}$ were made. Then, the MCC sample was pressed in a vacuum mold $\left(10^{-2}\right.$ $\mathrm{mm} \mathrm{Hg}$ ) between films of aluminum and polyethylene at $105{ }^{\circ} \mathrm{C}$ (to avoid moisture absorption of the sample). After this, the sample of MCC, in a capsule made of polyethylene with $\mathrm{Al}$ electrodes pressed to it, was placed in a thermostated four-electrode cell, which allows controlling the thickness of the sample during measurements using an additional air condenser.

The capacity and loss factor were measured at four fixed frequencies $f=5,10,20$ and $50 \mathrm{kHz}$, within the temperature range of $(-180 \div 120){ }^{\circ} \mathrm{C}$. An automated setup based on the alternating-current bridge P5083 was used. ${ }^{8}$ When calculating complex dielectric permittivity, we used data for an empty polyethylene capsule for the calibration. This method is described in a previous work. ${ }^{8}$

Fourier transform infrared (FTIR) measurements were performed on a Nicolet Nexus 470 spectrometer in the transmittance mode (spectral range of 625-4000 $\mathrm{cm}^{-1}$, resolution of $1 \mathrm{~cm}^{-1}$ ). For the measurements, the MCC samples were mixed with $\mathrm{KBr}$. To obtain the spectra at different temperatures, the samples were placed in a Variable Temperature Cell P/N 21525 with $\mathrm{NaCl}$ windows, the cell was evacuated to 0.1 Torr, cooled by liquid nitrogen to $-165^{\circ} \mathrm{C}$ and then heated at the heating rate of $2{ }^{\circ} \mathrm{C} / \mathrm{min}$. The spectra were recorded within the step of $\Delta \mathrm{T}=5{ }^{\circ} \mathrm{C}$.

\section{RESULTS AND DISCUSSION XRD analysis}

The XRD pattern of microcrystalline cellulose (Fig. 1) was recorded within the angle range of $2 \theta$ $[5 \div 45]^{\circ}$ with $0.1^{\circ}$ step. The powder XRD pattern of MCC could be represented as the sum of six peaks with periods of $5.9 \AA, 5.3 \AA, 4.3 \AA, 3.9 \AA$, $3.1 \AA$ and $2.6 \AA$. Their relation to cellulose crystalline planes is presented in Figure 1.

The degree of crystallinity $\left(C_{k}\right)$ of MCC was calculated using the XRD pattern, as the ratio of the intensity of structural reflexes to the total intensity of the diffraction pattern, except for the background in the range $2 \theta[5 \div 45]^{\circ}$ (Fig. 1)..$^{9}$ It was calculated that MCC $C_{k}=58 \%$. The transversal dimensions in the direction of normals to the system of plains (200) were calculated by the Debye-Scherrer formula (1):

$$
B_{200}=\frac{\mathrm{k} \cdot \lambda}{\mathrm{h} \cos \theta_{200}}
$$

where $k=0.94$ is a dimensionless form-factor, $\lambda$ is the wavelength of $\mathrm{CuK} \alpha$ radiation $(1.54178 \AA), h$ is the half-width of the (200) reflex, $\theta_{200}$ is the angle of diffraction from the plains system (200).

The instrumental broadening of peak width was taken into account, using the half-width of the reflex in the powder pattern of a reference sample (highly crystalline urotropine). The resulted value of $B_{200}$ appeared equal to $4.58 \mathrm{~nm}$ for the dried-up MCC, i.e. the radius of a microcrystalline cellulose particle is $R=2.29 \mathrm{~nm}$. The longitudinal dimensions of the crystallites in the system of planes (004) were calculated in the same way as for the system (200) and equalled to $\mathrm{H}=6.10 \mathrm{~nm}$.

\section{Thermogravimetric and differential thermal analyses}

Thermogravimetric analysis (TGA) and differential thermogravimetric analysis (DTGA) (Fig. 2) were performed within the temperature range of $(20 \div 250){ }^{\circ} \mathrm{C}, \Delta \mathrm{T} / \Delta \mathrm{t}=5{ }^{\circ} \mathrm{C} / \mathrm{min}$ using the derivatograph for thermal and gravimetrical investigations of MCC.

The TGA curve (black curve) shows a weight loss of the sample in the range of $(80 \div 200){ }^{\circ} \mathrm{C}$, accompanied by the decrease noted on the DTGA curve. The value of the weight loss is $0.4 \%$. This weight loss is most probably caused by bound moisture evaporation. ${ }^{6,7}$ Thus, it could be 
concluded that, despite all the stages of drying, the investigated MCC still contained $0.4 \%$ moisture.

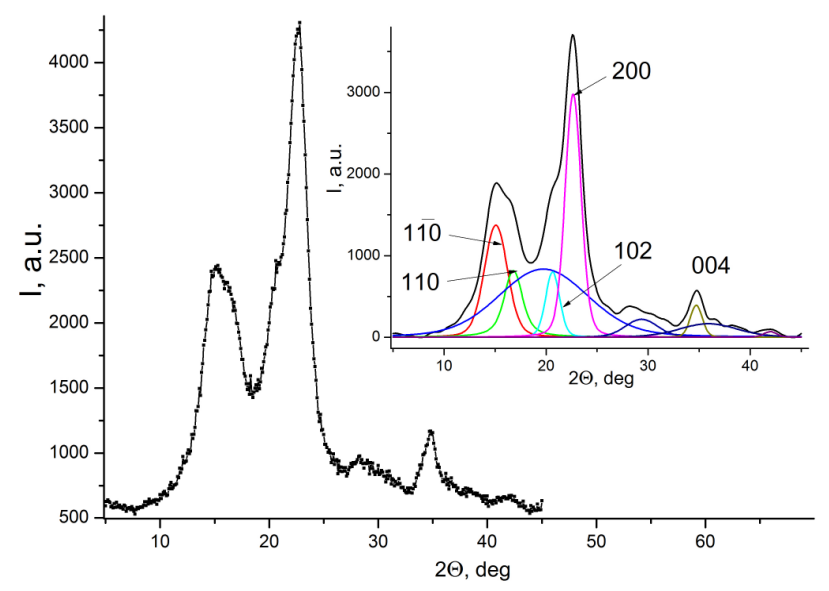

Figure 1: Powder XRD pattern of MCC and its representation as sum of components

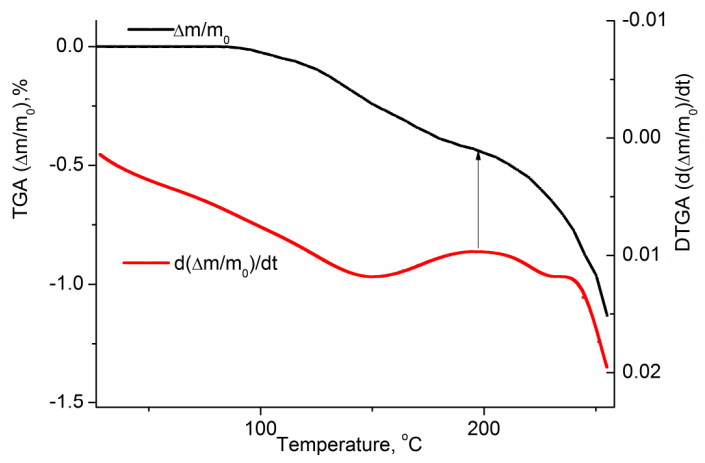

Figure 2: TGA (black curve) and DTGA (red curve) temperature dependence for MCC

\section{Dielectric properties of $\mathrm{MCC}$}

Temperature dependences of real and imaginary parts of complex dielectric permittivity within the temperature range of $(-180 \div 130){ }^{\circ} \mathrm{C}$, at field frequency $\mathrm{f}=5,10,20,50 \mathrm{kHz}$, were measured (see Figs. 3 and 4).

Temperature dependences of the imaginary component of the complex dielectric permittivity of MCC indicate a maximum that shifts to a higher temperature when the frequency increases (Fig. 4). The frequency dependence of $\mathrm{T}_{\max }$ allows relating this maximum to the relaxation process that occurs in MCC. A similar behavior of complex dielectric permittivity is described in the work of J. Einfeldt et al., ${ }^{4}$ for a dried cellulose sample. In this article, the authors suggest that the observed process is connected with $\beta$-relaxation, and therefore with the local mobility of the main polymer chain (dipole-segmental mobility). However, the detailed molecular mechanism of this mobility for a rigid cellulose chain is not discussed in Einfeldt's article. The absence of a maximum on the temperature dependencies of dielectric permittivity at $95{ }^{\circ} \mathrm{C}$ for this sample with humidity of $4.3 \%$ is the evidence that free water is absent from this sample. ${ }^{10}$ 


\section{Molecular model of the dielectric relaxation process}

In Figure 5a, the surface layer of the cellulose crystal is shown. ${ }^{11}$ It should be remarked that the cellulose molecules are connected by hydrogen bonds with each other. Let us consider the nature of the bonds by which the encircled hydroxymethyl group in $t g$ conformation is connected on the surface of the cellulose crystal. One covalent bond (1) connects it with the glucose cycle, one hydrogen bond (2) connects it with the $\mathrm{OH}$ group of the same molecule and one hydrogen bond (3) connects a hydroxymethyl

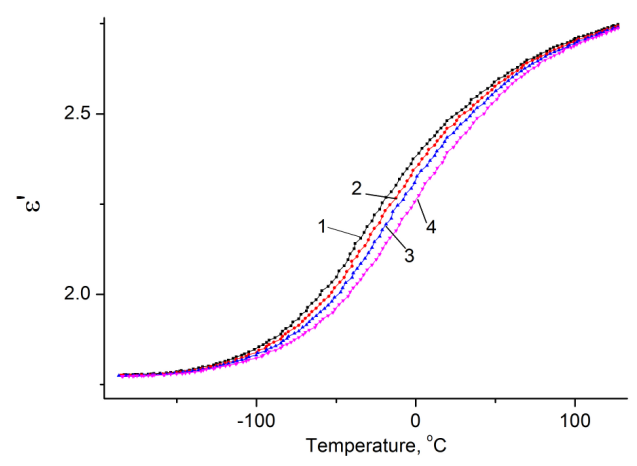

Figure 3: Temperature dependence of the real part of MCC dielectric permittivity at field frequencies of 1) $5 \mathrm{kHz}$, 2) $10 \mathrm{kHz}$, 3) $20 \mathrm{kHz}$, 4) $50 \mathrm{kHz}$

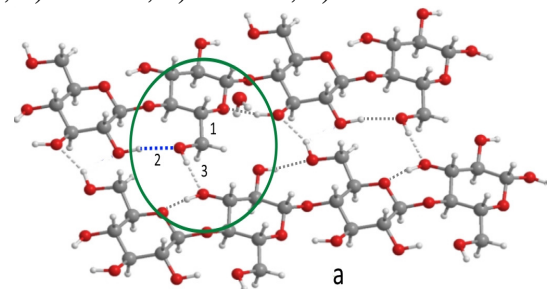

group with the $\mathrm{OH}$ group of neighboring molecules. The hydroxymethyl group located on the surface of the crystal can perform conformational motion around the bond (1), changing the conformation from $t g$ to $g t$. In his work, P. Chen ${ }^{12}$ calculated the energy of the molecule of cellulose with methylol groups in $t g$ $g t$ conformations without taking into account both the internal molecular bonds and the hydrogen bonds with the surrounding ones. It is shown that their energies are the same.

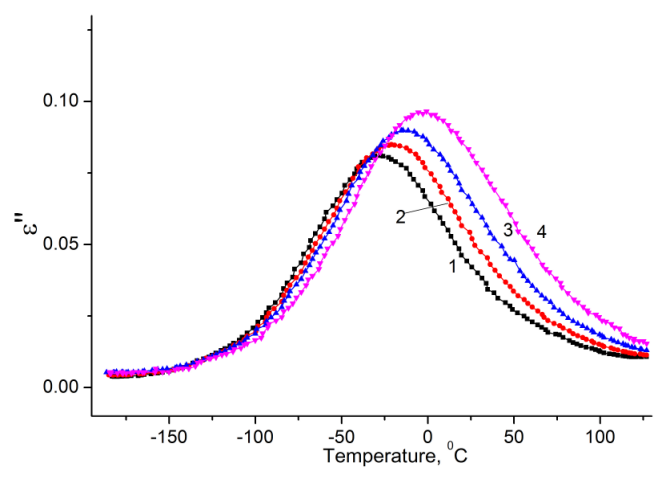

Figure 4: Temperature dependence of the imaginary part of MCC dielectric permittivity at field frequencies of 1) $5 \mathrm{kHz}$, 2) $10 \mathrm{kHz}$, 3) $20 \mathrm{kHz}$, 4) $50 \mathrm{kHz}$

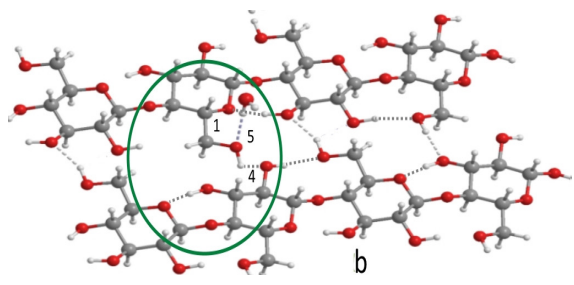

Figure 5: Fragment of cellulose crystal surface; a) $t g$ conformation of hydroxymethyl group is encircled, b) $g t$ conformation of hydroxymethyl group is encircled ${ }^{11}$

The hydroxymethyl group in the $g t$ conformation forms a hydrogen bond with an $\mathrm{OH}$ group of neighboring molecules (4) and a hydrogen bond with a water molecule (5), if the surface layer has a hydration shell (Fig. 5b). Intramolecular and intermolecular hydrogen bonds in cellulose have the energy of $25 \mathrm{~kJ} / \mathrm{mol}$, ${ }^{13}$ while the energy of the hydrogen bonds between the molecules of cellulose and water is about 18$21 \mathrm{~kJ} / \mathrm{mol}^{14}$ Therefore, the energy difference between the conformations $t g$ and $g t$ of the methylol group in cellulose molecules on the surface of the crystal is $V_{t}=4-7 \mathrm{~kJ} / \mathrm{mol}$, taking into account the energies of possible hydrogen bonds.

The dipole moment of the hydroxymethyl group ( $\mu_{\mathrm{CH}_{2} \mathrm{OH}}$ ) was calculated as the vector sum of the dipole moments of the valent bonds that compose this fragment. According to the literature data, $\quad \mu_{\mathrm{CH}}=0.4 \mathrm{D}, \quad \mu_{\mathrm{OH}}=1.58 \mathrm{D} \quad$ and $\mu_{\mathrm{OC}}=1.11 D{ }^{15,16}$ Taking into consideration the spatial structure of the hydroxymethyl group, its dipole moment was estimated as $\mu_{\mathrm{CH}_{2} \mathrm{OH}}=2.09 \mathrm{D}$. When a reorientation from $t g$ conformation to $g t$ 
conformation occurs, the dipole moment changes, and the value of the change is $\mu_{\text {teor }}=2.52 \mathrm{D}=8.316 \cdot 10^{-30} \mathrm{C} \cdot \mathrm{m}$.

To calculate the parameters of the relaxation process, we apply a model, where there is a system of identical relaxation oscillators (relaxers), and each of them has two energetically non-equivalent positions divided by the potential barrier.

Then, for this model, the dependence of the real and imaginary parts of the complex dielectric constant can be written as follows: ${ }^{17}$

$\varepsilon^{\prime}(\omega, T)=\varepsilon_{\infty}+\frac{\Delta \varepsilon(T)}{1+\omega^{2} \tau^{2}(T)}$

$\varepsilon^{\prime \prime}(\omega, T)=\frac{\Delta \varepsilon(T) \omega \tau(T)}{1+\omega^{2} \tau^{2}(T)}$

The work of J. D. Hoffman et al. ${ }^{17}$ demonstrated that, in such a model, only one relaxation time $(\tau)$ exists:

$\tau=\frac{2 \pi}{\omega_{0}} \frac{\exp (U / k T)}{1+\exp (-V / k T)}$

and for the increment of dielectric permittivity, formula (4) is valid:

$\Delta \varepsilon=\varepsilon_{0}-\varepsilon_{\infty}=\frac{N \mu^{2}}{3 k \varepsilon_{0} T} \cdot \frac{\exp (-V / k T)}{[1+\exp (-V / k T)]^{2}}$

where $N$ is the concentration of relaxers, $\mu^{2}$ is the mean square of the difference of dipole moments of relaxers in positions 1 and 2.

Taking into account the condition of maximum $\varepsilon^{\prime \prime}(T, f)$ (Eq. 3) $\omega \tau=1$ and using the Arrhenius dependence $\ln f(1 / T)$ (Fig. 6) for processing the experimental data (Fig. 4), the activation energy was obtained. We estimated it as $U_{\exp }=50$ $\mathrm{kJ} / \mathrm{mol}$.

Further, the potential barrier for the hydroxymethyl group movement was calculated, considering this group as a relaxer. The hydroxymethyl group has two hydrogen bonds with the neighboring groups (Fig. 5), and each of these bonds has an energy of $25 \mathrm{~kJ} / \mathrm{mol}$. For this reason, when a hydroxymethyl group transits from $t g$ to $g t$ conformation, it has to break two hydrogen bonds and overcome the potential barrier of $5 \mathrm{~kJ} / \mathrm{mol}$ when changing the torsion angle. So, the total barrier value is $U_{\text {teor }}=55$ $\mathrm{kJ} / \mathrm{mol}$. This value is consistent with the value $U_{\text {exp }}$ calculated from the experimental data.

Approximating the dependence of the real part of the complex dielectric permittivity for Cellets 100 , with moisture content of $0.4 \%$, by the relation (5), we obtain the values $\mathrm{M}^{2}$ exp $=N_{\exp }$ $\mu_{\text {exp }}^{2} /\left(3 \mathrm{k} \varepsilon_{0}\right)=2300 \mathrm{~K}$ and $V_{\text {exp }}=6.7 \mathrm{~kJ} / \mathrm{mol}$.

The experimentally obtained energy difference $V_{\text {exp }}=6.7 \mathrm{~kJ} / \mathrm{mol}$ between the conformations $t g$ and $g t$ of the hydroxymethyl groups can be explained by the fact that the hydroxymethyl group in the $t g$ conformation has a hydrogen bond with the $\mathrm{OH}$ group (the energy of this bond is 25 $\mathrm{kJ} / \mathrm{mol}$ ) and the hydroxymethyl group in the $t g$ conformation has a hydrogen bond with a water molecule and the energy of this bond is 18 $\mathrm{kJ} / \mathrm{mol}$.

The structure of the elementary cell of MCC crystals was investigated by Y. Nishiyama et al. ${ }^{11}$ The volume of the cell1 1 is $\mathrm{V}=658.3 \AA^{3}$. It includes ten hydroxymethyl groups. Then, the concentration of the hydroxymethyl groups can be calculated according to the formula: $N_{\text {teor }}=n / V=15.2 \cdot 10^{27} \mathrm{~m}^{-3}$, where $n=10$ is the number of groups in the elementary cell. Thus, $\mathrm{M}_{\text {teor }}^{2}=N_{\text {teor }} \mu_{\text {teor }}^{2} /\left(3 \mathrm{k} \varepsilon_{0}\right)=2870 \mathrm{~K}$.

From here, it follows that the input into the dipole relaxation polarization is made by the reorientation of only some part of the hydroxymethyl groups, namely $\gamma_{\text {exp }}=N_{\text {exp }} / N_{\text {teor }}=\mathrm{M}_{\text {exp }}^{2} / \mathrm{M}_{\text {teor }}^{2}=0.8$.

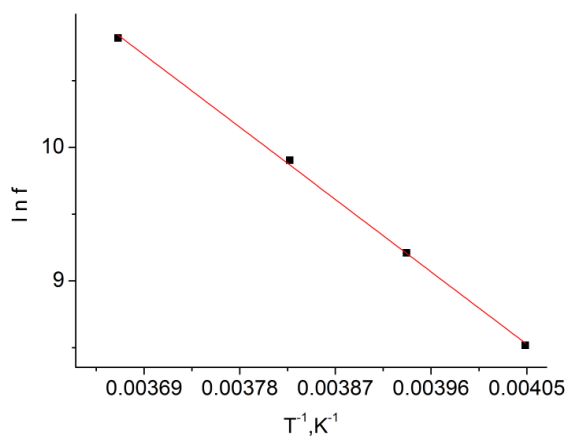

Figure 6: Dependence of the logarithm of frequency on $\mathrm{T}^{-1}$ 


\section{OLEXANDER M. ALEKSEEV et al.}

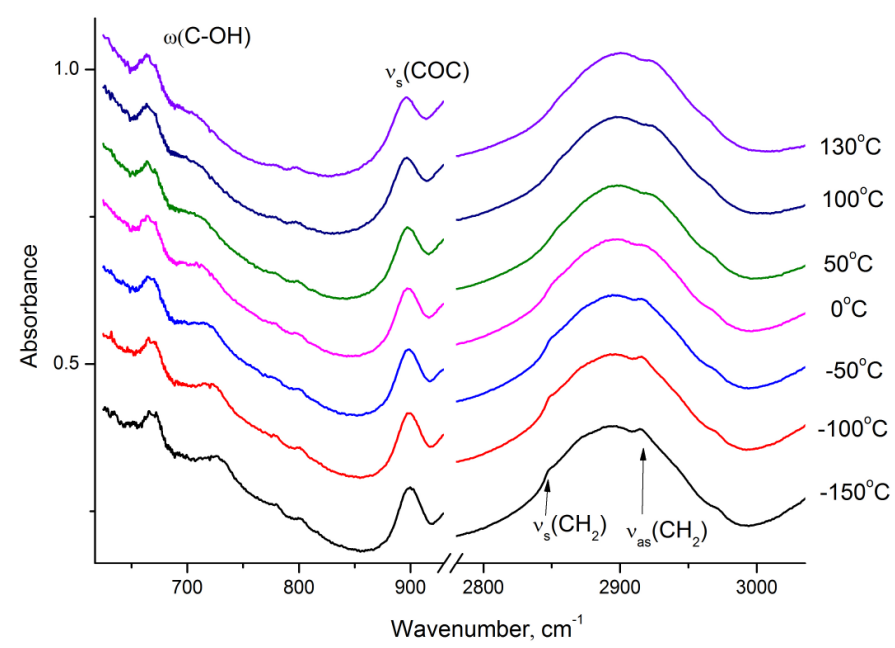

Figure 7: FTIR spectra of MCC at different temperatures

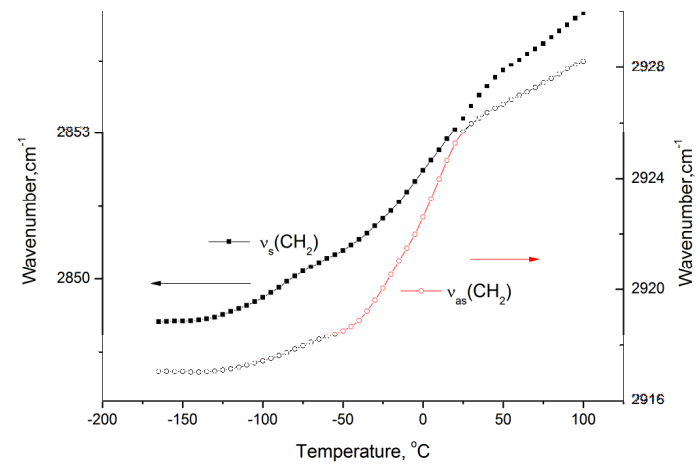

Figure 8: Temperature dependence of asymmetric and symmetric valence fluctuations of methylene groups

To determine the ratio between the amount of methylol groups on the surface of the crystallite $\mathrm{N}_{\mathrm{s}}$ and in the crystallite volume $\mathrm{N}_{\mathrm{v}}$, we assumed that its side surface includes one layer of cellulose molecules. The thickness of this layer is $d_{1}=(a+$ b) $/ 2$, where $\mathrm{a}=0.778 \mathrm{~nm}, \mathrm{~b}=0.820 \mathrm{~nm}, \mathrm{c}=1.03$ $\mathrm{nm}$ are parameters of the unit cell of cellulose. ${ }^{11}$ For the end face surface, the thickness of this layer is $\mathrm{d}_{2}=\mathrm{c} / 2=0.515 \mathrm{~nm}$. Then, taking into account the crystallite sizes determined above, we obtain the relation $\gamma_{\mathrm{c}}=\mathrm{N}_{\mathrm{s}} / \mathrm{N}_{\mathrm{v}}=\mathrm{V}_{\mathrm{s}} / \mathrm{V}=1$ - $(\mathrm{R}$ $\left.\mathrm{d}_{1}\right)^{2}\left(\mathrm{H}-2 \mathrm{~d}_{2}\right) /\left(\mathrm{R}^{2} \mathrm{H}\right)=0.65$.

Taking into account the experimentally determined degree of crystallinity $\mathrm{C}_{\mathrm{k}}=0.58$, and also assuming that all the methylol groups in the amorphous regions also participate in the relaxation process $\left(\gamma_{\mathrm{a}}=1\right)$, we find that the fraction of the methylol groups whose motion contributes to the relaxation process is $\gamma_{\mathrm{t}}=\gamma_{\mathrm{a}}$ (1$\left.\mathrm{C}_{\mathrm{k}}\right)+\gamma_{\mathrm{c}} \mathrm{C}_{\mathrm{k}}=0.8$.

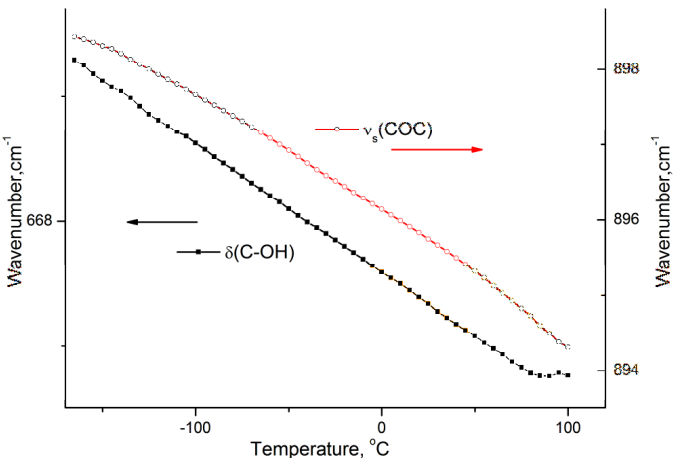

Figure 9: Temperature dependence of oscillations of glycoside bonds between glucose units in cellulose and deformation oscillations of hydroxyl groups

A comparison of our experimental results and model estimates of the contribution of the conformational reorientation $\operatorname{tg} \leftrightarrow$ gt of the hydroxymethylene groups on the surface of MCC crystallites and in their amorphous (defective) regions allows suggesting that this molecular mechanism plays an important role in the observed relaxation process. However, in the paper by J. Einfeldt et al., ${ }^{4,5}$ on the basis of the absence of such a process in glucose, the authors assumed its exclusively dipole-segmental nature. We carried out investigations of the IR spectra of the MCC in a wide temperature range $(-160 \div$ 130) ${ }^{\circ} \mathrm{C}$. Similar studies carried out by us earlier $^{18,19}$ allowed obtaining additional information about the nature of the relaxation processes and phase transitions in systems of aliphatic molecules. The presence of hydrogen bonds in the systems can lead to a great change of 
Microcrystalline cellulose

the natural vibrations of molecules, in comparison with isolated molecules. ${ }^{20}$

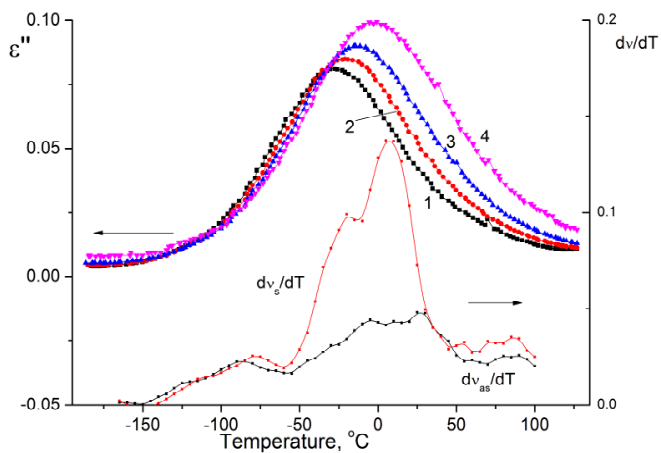

Figure 10: Temperature dependence of derivatives of asymmetric and symmetric valence fluctuations of methylene groups and the imaginary part of dielectric constant for MCC

We carried out the analysis of the IR spectra obtained in the region of valent vibrations of the $\mathrm{CH}_{2}$ groups $v_{\mathrm{s}}\left(\mathrm{CH}_{2}\right)$ and $v_{\text {as }}\left(\mathrm{CH}_{2}\right),{ }^{21}$ which exist only in the methoxyl radicals of the cellulose molecule, as well as the analysis of the vibrations of the groups connected with the pyranose ring, $\omega(\mathrm{C}-\mathrm{OH})(\mathrm{C}-\mathrm{OH}$ out-of-plane bending $),{ }^{22}$ and with the polymer chain, $v_{\mathrm{s}}$ (COC) (symmetric ring-stretching mode of glycosidic bonds). ${ }^{22}$

In Figures 8 and 9, the temperature dependences of the IR absorption bands are presented, as well as the temperature dependences of their derivatives (Fig. 10), in the region of the observed process of dielectric relaxation. It can be seen that the behavior of the temperature dependences of the IR absorption bands associated with the groups from the pyranose ring and the bands associated with the methoxyl radical are qualitatively different (the temperature dependence of the absorption maximum for the $\mathrm{CH}_{2}$ group exhibits a bend, while no bend is present on the temperature dependence of the absorption maximum for the groups $\mathrm{C}-\mathrm{OH}$ and COC) (Figs. 8, 9). We believe that this situation confirms a possible contribution of the $\operatorname{tg} \leftrightarrow \mathrm{gt}$ reorientation of methylol radicals to the observed relaxation process in $\mathrm{MCC}$.

\section{CONCLUSION}

Relaxation, which is observed on the temperature dependence of the complex dielectric permittivity for MCC, could be connected with the $t g \leftrightarrow g t$ conformation reorientation of the hydroxymethyl groups on the surface of microcrystalline cellulose particles and in its amorphous regions.
ACKNOWLEDGMENT: The authors thank Harke Group Company for providing the MCC samples.

\section{REFERENCES}

1 F. Roig, E. Dantras, J. Dandurand and C. Lacabanne, J. Phys. D: Appl. Phys., 44, 045403 (2011), https://iopscience.iop.org/article/10.1088/00223727/45/29/295402/meta

2 D. Le Bras, M. Strømme and A. Mihranyan, J. Phys. Chem. B, 119, 5911 (2015), https://doi.org/10.1021/acs.jpcb.5b00715

3 T. I. Borisova, G. A. Petropavlovskiia and N. Ye. Kotel'nikova, Polym. Sci. USSR, 21, 2240 (1979).

4 J. Einfeldt, D. Meißner and A. Kwasniewski, Progress Polym. Sci., 26, 1419 (2001), DOI: 10.1016/S0079-6700(01)00020-X

5 J. Einfeldt, D. Meißner and A. Kwasniewski, Cellulose, 11, 137 (2004), https://doi.org/10.1023/B:CELL.0000025404.61412.d6 6 V. Y. Pichkur, M. M. Lazarenko, O. M. Alekseev, V. M. Kovbasa and M. V. Lazarenko, EasternEuropean Journal of Enterprise Technologies, 1, 52 (2015), 4061.2015.33116

7 N. Prytulska, D. Fedorova, M. Lazarenko, O. Vasylieva and T. Yudina, Eastern-European Journal of Enterprise Technologies, 6, 22 (2016), https://doi.org/10.15587/1729-4061.2016.86435

A. N. Alekseev, M. M. Lazarenko, M. V. Lazarenko, K. N. Kovalev and S. Yu. Tkachev, Inorg. Mater., $\quad \mathbf{5 3}, \quad 1473 \quad$ (2017), https://doi.org/10.1134/S002016851715002X

9 K. Leppeanen, S. Andersson, M. Torkkeli, M. Knaapila, N. Kotelnikova et al., Cellulose, 16, 999 (2009), https://doi.org/10.1007/s10570-009-9298-9 


\section{OLEXANDER M. ALEKSEEV et al.}

10 K. M. Kovalov, O. M. Alekseev, M. Lazarenko and S. Yu. Tkachov, Nanoscale Res. Lett., 12, 468 (2017), https://doi.org/10.1186/s11671-017-2231-5

11 Y. Nishiyama, P. Langan and H. Chanzy, J. Am. Chem.-Soc., $\quad 124, \quad 9074 \quad$ (2002), https://doi.org/10.1021/ja0257319

12 P. Chen, Y. Nishiyama and K. Mazeau, Macromolecules, $\quad \mathbf{4 5}, \quad 362 \quad$ (2012), https://doi.org/10.1021/ja037055w

13 A. M. Bochek and G. A. Petropavlovsky, Cellulose Chem. Tehnol., 27, 587 (1993).

14 M. V. Radugin, T. N. Lebedeva, A. N. Prusov and A. G. Zakharov, Russ. J. Phys. Chem. A., 84, 1478 (2010), https://doi.org/10.1134/S0036024410090049

15 O. Exner, "Dipole Moments in Organic Chemistry”, Stuttgart, 1975, 156 pp.

16 T. Uchida, Y. Kurita and M. Kubo, J. Polym. Sci., 19, 365

(1956), https://doi.org/10.1002/pol.1956.120199215

17 J. D. Hoffman, G. Williams and E. Passaglia, J. Polym. Sci.: Polym. Symp., 11, 173 (1966), https://doi.org/10.1002/polc.5070140116
18 O. M. Alekseev, M. M. Lazarenko, G. O. Puchkovs'ka, T. V. Bezrodnaya and A. A. Sendzyuk, Ukr. J. Phys., 55, 972 (2010).

19 O. M. Alekseev, S. O. Alekseev, L. A. Bulavin, M. M. Lazarenko and O. M. Maiko, Ukr. J. Phys., 53, 882 (2008).

20 L. M. Babkov, J. Baran et al., J. Mol. Struct., 55, 700 (2004), https://doi.org/10.1016/j.molstruc.2003.12.050 21 C. Y. Liang and R. H. Marchessault, J. Polym. Sci., 37, 385

(1959),

https://doi.org/10.1002/pol.1959.1203713209

22 M. Le Troedec, D. Sedan, C. Peyratout, J. P. Bonnet, A. Smith et al., Compos. Part A, 39, 514 (2008), doi: 10.1016/j.compositesa.2007.12.001. 